\title{
ICT Development at University of Mines and Technology (UMaT)*
}

\author{
S. K. Asiedu-Asante and V. A. Temeng
}

Asiedu-Asante, S. K. and Temeng, V. A. (2010), "ICT Development at University of Mines and Technology (UMaT)", Ghana Mining Journal, Vol. 12, pp. 58 - 62.

\begin{abstract}
The University of Mines and Technology (UMaT) has adopted IT and later ICT to enhance, teaching, learning and research for sometime now and in this paper the authors who were part of the team that introduced ICT at UMaT describe this adoption of ICT. The concept of ICT preparedness index is introduced and used to assess the advancement of UMaT in the areas that are most critical to the adoption of ICT in a university and to identify areas of strength and weakness in ICT at UMaT.
\end{abstract}

\section{Introduction}

Computers (hardware and software) were originally developed for computation. This role of computers changed to include conversion, storage, protection, processing, transmission, and retrieval of information which is referred to as information technology (IT). The addition of communication channels to IT, such as the Internet or other information services, has significantly extended the capability of the computer. The fusion of IT and telecommunication is called Information and Communication Technology (ICT). ICT is not only an inexpensive communications tool, but also a means of enhancing teaching, learning, research, information gathering, and working with others irrespective of geographical barriers. Because of these capabilities of ICT, many educational institutions worldwide have adopted the use of ICT. The adoption of this technology in a university in a developing country is not a straight forward issue. There are problems such as lack of personnel who actually understand ICT to advice on selection and building of the appropriate infrastructure, consultants to design and build the infrastructure, personnel to man, manage, and teach others how to use the ICT infrastructure and problems associated with funding.

The University of Mines and Technology (UMaT) adopted IT and later ICT to enhance teaching and learning, research, academic information services (library) and administration and Management Information System (MIS) for sometime now. In this paper the authors who were part of the team that introduced ICT at UMaT share their experiences on ICT infrastructure design and its applications, the problems associated with personnel and funding at UMaT.
Since ICT technology and its application are advancing every day, it is necessary to assess this advancement periodically in areas (teaching, learning, research, etc.) that are most critical to the university so as to identify strategic priorities for improvement.

ICT preparedness index, a method which was used to assess the advancement of ICT at UMaT is also presented.

\section{Historical Development of ICT at UMaT}

The University of Mines and Technology started in 1952 as the Tarkwa Technical Institute. In 1961, it was reorganized to become the Tarkwa School of Mines to train the required manpower for the mining and allied industries in Ghana. In 1976, the school was affiliated to the Kwame Nkrumah University of Science and Technology (KNUST) as a faculty of the University. In 2001, it became the Western University College of KNUST. The Western University College of KNUST became UMaT on $11^{\text {th }}$ November 2004 by an Act of Parliament of Ghana (Act 677).

During this transformation to an autonomous university, a number of organizations of which the German Agency for Technical Co-operation (GTZ) was among provided assistance to the University in many areas including Information Technology (IT). In 1985, GTZ provided two IBM personal computers systems (PC), a dot matrix printer and a UPS to the then School of Mines to setup the first computer laboratory. The PCs had $256 \mathrm{~Kb} \mathrm{RAM}, 20 \mathrm{Mb}$ hard disks and one had a monochrome monitor and the other was a colour monitor. Considering the fact that IBM PC first appeared on the world market in 1981, the then

\footnotetext{
* Manuscript received March 11, 2010

Revised version accepted October 15, 2010
} 
School of Mines was among the IT pioneers in Ghana. The laboratory was air conditioned and the windows were provided with long curtains to prevent dust from entering the machines. These measures prolonged the life of the PC's. The GTZ and the School later increased the number of PCs to enable the laboratory handle a class of forty students at a time. In addition, the course structures of all academic departments were modified to include a course known as "Introduction to Computing". This course introduced students to computer hardware and software, operating systems, word processing, spreadsheet, database and basic programming. Short courses on Introduction to Computing were also run for lecturers and staff of the university.

In 1999, another course, Computer Applications, was added to the course structures to introduce students to the application of computers in their various fields of study. For this, extra equipment like digitizers and plotters as well as educational licenses for expensive specialised software like Surpac, Datamine, Archview were acquired for mining, geological and geomatic engineering specialities. A Computer Aided Design (CAD) software was also purchased for the electrical and mechanical engineering departments. The administrative offices were also provided with PCs but lecturers were encouraged with loans to purchase their PCs. At the end of year 2000, it had become evident that the introduction of IT had improved greatly the quality of work at the School. Lecturers produced well prepared handouts for students, students presented neat project reports with less spelling mistakes, the pay roll of the School was promptly prepared at the end of each month and the administrators produced the various documentations faster and neater.

In 2001, the then University College joined the ICT community by adding an Internet cafe using the dial-up system to the computing facilities. The café could sit about forty people and lecturers and staff had a separate section for browsing. Considering the unreliability and low speed of the dial-up system, the University decided to build a system consisting of a Wireless Local Area Network (WLAN) and Internet via Very Small Aperture Terminal (VSAT), a satellite communication system.

\section{ICT Infrastructure at UMaT}

To build the WLAN and VSAT internet infrastructure, several companies were invited to submit proposals to build WLAN and Internet via VSAT. The evaluation of the submitted proposals showed that most of the companies did not have enough knowledge about the project. The equipment they proposed to use were of poor quality and could not have withstood the weather in Tarkwa. In selecting the most competent proposal, the prices and quality of equipment of the various proposals were verified on the Internet. To reduce the financial burden on the College in funding the project, the project was divided into phases and paid for on turn key basis after the completion of a phase. The subscription fee of the internet signal was to be paid by students, lecturers and the use of internally generated funds.

The design of the VSAT Infrastructure and Campus WLAN system are shown in Fig. 1. In this design, the Internet signal is received from a company Gilatsatcom in Israel through their LM1 satellite by $2.4 \mathrm{~m}$ diameter Master Channel Prodelin dish. Gilatsatcom provides reliable service and its Internet subscription fee is low. From the dish, the down link signal is routed through the Digital Pro C-band LNB and DVD-Receiver to the WAN switch. The signal then comes to the LAN switch for distribution through a Linux fire wall. The signal coming from the LAN switch goes to a centrally placed omni-directional antenna which transmits and also receives signals from remote LANs.

Every building block has its own local area network which is referred to as remote LAN. All rooms in a building block are provided with at least one access point. Large rooms like classrooms and lecture halls and conference rooms in a building block are provided with radio access points to allow more computers in and around the buildings to be connected at the same time. Residential halls are also provided with radio access points. This enables students to browse the Internet in their cubicles. Building blocks that are far from the main campus are linked to the system by 10 $\mathrm{km}$ range wireless bridge.

The uplink signal passes through the fire wall, the router, satellite modem, the C-band BUC and to the dish. The system presently has four servers namely, directory server (S1), mail server (S2), library server (S3) and an applications server (S4).

To overcome power cuts and power fluctuations problems, a power pack system consisting of 12 volts car batteries, a stabilizer and an inverter that can supply power to the servers and the equipment in the server room for about 12 hours is used instead of conventional UPS. Anon (2001) gives the design procedure of such a power backup system.

\section{ICT Preparedness of UMaT}

The level of advancement in ICT technology and its applications vary from one community to another and within a particular community can vary with time. It is therefore natural for a community to assess its level of advancement in ICT periodically and use the assessment to identify its strategic priorities in ICT. 


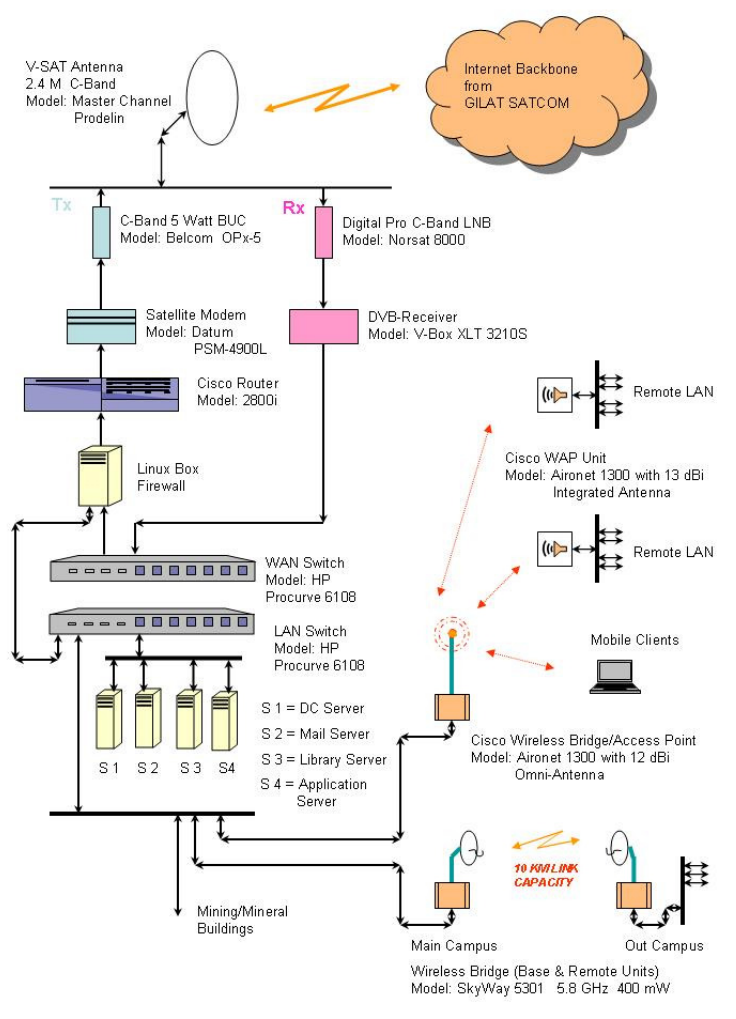

Fig.1 VSAT Infrastructure and Campus Wireless LAN Deployment at University of Mines and Technology, Tarkwa
ICT preparedness index also called e-Readiness index, can be used to assess a community's advancement in areas that are most critical to the adoption of ICT in the community (Anon, 2002a). The Ghanaian Universities ICT Preparedness Assessment Model (GUIAM) which is a modification of the Bulgarian e-Readiness Assessment Model (BEAM) (Anon, 2002b), by Dakubu and Asiedu-Asante (2007) to take care of conditions in the Ghanaian Public Universities is used in this paper to determine the ICT preparedness index of UMaT.

The GUIAM consists of a carefully designed scaled questionnaire that covers seven major areas (categories) and their sub-categories that influence the level of advancement in ICT in Ghanaian Public Universities and evaluation of the responses to the questionnaire to produce ICT preparedness index. The seven categories are:

- Information Policy Plan;

- ICT in Teaching and Learning;

- Campus ICT infrastructure;

- Computers and software;

- ICT in Research;

- ICT in Academic Information Services: (Library/Archives);

- ICT in Administration \& Management (MIS).

The seven categories and their sub-categories are shown in Fig. 2. The questionnaire used was origi-

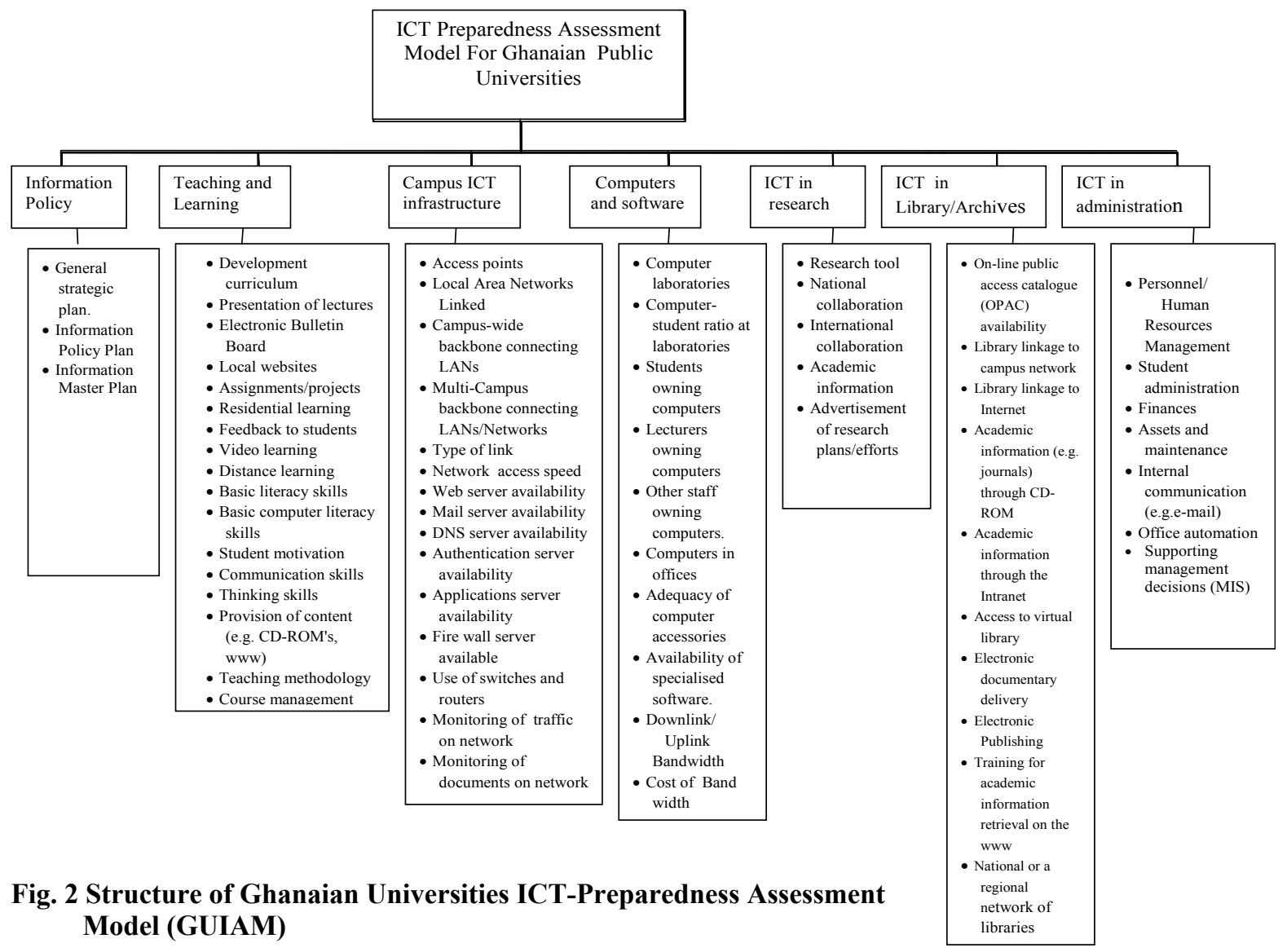


nally evolved by Adubifa and Association of African Universities (AAU) (2001) and modified to include the seven categories and their subcategories. Part of such a completed scaled questionnaire for campus ICT infrastructure category is as shown in Table 1.

Table 1 Part of 5-points Scaled Questionnaire for Campus Infrastructure Category

\begin{tabular}{|l|l|c|c|c|c|c|}
\hline & Sub-categories & $\begin{array}{c}\mathbf{1 = 0} \\
\mathbf{\%}\end{array}$ & $\begin{array}{c}\mathbf{3 = 1 - 2 6} \\
\mathbf{\%}\end{array}$ & $\begin{array}{c}\mathbf{5 = 2 7 - 5 0} \\
\%\end{array}$ & $\begin{array}{c}\mathbf{7 = 5 1 - 7 9} \\
\mathbf{\%}\end{array}$ & $\begin{array}{c}\mathbf{1 0 = > 8 0} \\
\%\end{array}$ \\
\hline 1 & $\begin{array}{l}\text { Percentage of offices with access } \\
\text { points }\end{array}$ & & & $\sqrt{ }$ & \\
\hline 2 & $\begin{array}{l}\text { Percentage of lecture rooms with } \\
\text { access points }\end{array}$ & $\sqrt{ }$ & & & \\
\hline 3 & $\begin{array}{l}\text { Percentage of laboratories with } \\
\text { access points }\end{array}$ & & $\sqrt{ }$ & & \\
\hline 4 & $\begin{array}{l}\text { Percentage of rooms in libraries } \\
\text { with access points }\end{array}$ & & $\sqrt{ }$ & & \\
\hline 5 & $\begin{array}{l}\text { Percentage of rooms of hall of } \\
\text { residence with access points }\end{array}$ & & & $\sqrt{ }$ & & \\
\hline
\end{tabular}

Table 2 Rank and Importance Weighting Coef ficient Entries and the Infrastructure Index for the Infrastructure Category

\begin{tabular}{|l|l|c|c|c|c|}
\hline & \multicolumn{1}{|c|}{ Sub-categories } & Rank & Weight & $\begin{array}{c}\text { Rank multiplied } \\
\text { by Weight }\left(\mathbf{B}^{*} \mathbf{C}\right)\end{array}$ & $\begin{array}{c}\text { Index } \\
\sum \mathbf{D} / \Sigma \mathbf{C}\end{array}$ \\
\hline \hline & A & $\mathrm{B}$ & $\mathrm{C}$ & $\mathbf{D}$ & $\mathrm{I}$ \\
\hline \hline 1 & $\begin{array}{l}\text { Percentage of offices with access } \\
\text { points }\end{array}$ & 7 & 2 & 14 & 7 \\
\hline 2 & $\begin{array}{l}\text { Percentage of lecture rooms with } \\
\text { access points }\end{array}$ & 3 & 2 & 6 & 3 \\
\hline 3 & $\begin{array}{l}\text { Percentage of laboratories with } \\
\text { access points }\end{array}$ & 5 & 1 & 5 & 5 \\
\hline 44 & $\begin{array}{l}\text { Percentage of rooms in libraries with } \\
\text { access points }\end{array}$ & 5 & 2 & 10 & 5 \\
\hline 5 & $\begin{array}{l}\text { Percentage of rooms of hall of } \\
\text { residence with access points }\end{array}$ & 5 & 1 & 5 & 5 \\
\hline & \multicolumn{2}{|l|}{} \\
\hline
\end{tabular}

\section{Construction of ICT Preparedness Index}

The construction of ICT preparedness index involved a number of steps:

i. A 5-point scaled questionnaire for each of the seven ICT category indicators of the GUIAM was designed. On this 5-point scale a rank of 1 is assigned to the first value, a rank of 3 to the second value, a rank of 5 to the third value, a rank of 7 to the fourth value and a rank of 10 to the fifth value. A rank of 1 has the minimum value and rank of 10 has highest value.

ii. An ICT expert examined the seven ICT category indicators at UMaT and provided the appropriate responses to the questionnaire. Table 1 shows an example of a 5-point scaled questionnaire for the category; campus infrastructure with responses.

iii.Each sub-category was divided into two groups depending on their importance to this preparedness assessment. The level of importance is measured on a 2-point scale ("low" and "high") based on expert assessment.
High-importance sub-categories are weighted by 2 and low-importance ones are weighted by 1 in the computation of the indices.

iv. Table 2 was created and the relevant rank and weighting values inserted.

v. Each rank was multiplied by its corresponding importance weighting coefficient $\left(B^{*} \mathrm{C}\right)$ to obtain the weighted ranks as in column $\mathrm{D}$ in Table 2.

vi. The value of each category index was computed as a sum of the weighted ranks of the respective variables included in a given subcategory divided by sum of weighting coefficients $\left(\sum \mathrm{D} / \sum \mathrm{C}\right)$ as in column I Table 2.

Each category index summarizes the indices of its subcategories and is presented in a statistically normalized form from 0 to 10 . Values closer to 0 indicate a "low level" of ICT preparedness in the respective category and those closer to $10-\mathrm{a}$ "high" state of ICT preparedness.

The ICT preparedness index for each of the seven categories was similarly computed and their aggregate ICT preparedness index was computed as an average value of the indices for different categories as shown in Table 3.

Table 3 shows the computed ICT preparedness indices for the seven ICT categories of the GUAIM as well as their average which is the ICT preparedness index of UMaT as at July 2008.

The ICT preparedness index for each of the seven categories can be presented as a radar chart as shown in Figure 3 for better visualization of the weaknesses / strengths of each category.

Table 3 ICT Preparedness Indices for Seven Categories and their Average for UMaT as at July 2008

\begin{tabular}{|l|c|}
\hline Category & Index \\
\hline Information Policy & 3.25 \\
\hline Teaching and Learning & 1.35 \\
\hline ICT infrastructure & 7.30 \\
\hline Computers and software & 4.00 \\
ICT in Research & 1.71 \\
Library & 0.25 \\
ICT in Administration & 1.13 \\
Average & 2.71
\end{tabular}

\section{Discussion}

As can be seen from Table 3 or Fig.3, the ICT Preparedness index of UMaT as at July 2008 was 2.71. This low level can be attributed to the poor library category index of 0.25 , administration category index of 1.13 and teaching and learning category index of 1.35 . The ICT infrastructure category had the highest index of 7.3 meaning that the ICT infrastructure is well developed at UMaT. The 
library category index will soon improve when the installation of the library automation system currently going on is finished. The administration index can be improved by the use of ICT in personnel / human resources management, student administration, assets and maintenance and internal communication (e.g. e-mail). The teaching and learning category index can be improved by increasing the use of ICT in presentation of lectures and introduction of e-learning.

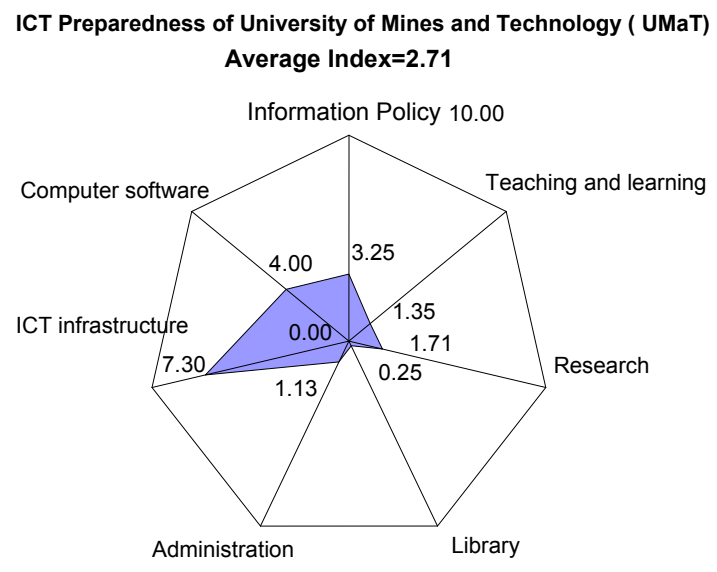

Fig. 3 ICT Preparedness Indices of Seven ICT Categories of UMaT as at July 2008.

\section{Conclusions}

The development of ICT at UMaT, problems associated with personnel and funding as well as their solutions have been highlighted. The level of advancement in ICT technology and its applications at UMaT as at July 2008 has been assessed using the concepts of ICT Preparedness index. The assessment produced ICT Preparedness index of 2.71 which indicates a low level of advancement in ICT technology and its applications at UMaT. The assessment also identified areas of strength and weakness in ICT technology and its applications at UMaT. The assessment must be carried out periodically.

\section{References}

Adubifa, O. A. and Association of African Universities (AAU). (2001), "Questionnaire to establish the state and application of ICT in the Universities", (Unpublished). $22 \mathrm{pp}$.

Anon. (2001), "SW Series Inverter/Charger", Owner Manual, Xantrex Technogy Inc., 142 pp.

Anon. (2002a), "Readiness for Networked WorldA guide for Developing Countries", www.readinessguide.org. Date accessed on: January 13, 2007, 22 pp.
Anon. (2002b), "Bulgaria: ICT Infrastructure and E-Readiness Assessment" www.arc.online.bg. Date accessed on: January 13, 2007, 85 pp.

Dakubu, M. and Asiedu-Asante, S. K. (2007), "Vice Chancellors Ghana's Position Paper on ICT preparedness of Ghanaian Public Universities", Unpublished. 23 pp.

\section{Authors}

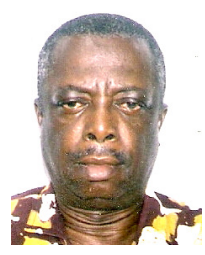

S. K. Asiedu-Asante obtained the MSc Degree in Mining Engineering from Friendship University, Moscow, in 1979 and Certificate in Oil Well Drilling Technology in 1985 from University of Texas. In 1995, he obtained a PhD from Kwame Nkrumah University of Science and Technology (KNUST), Kumasi, Ghana. He has worked as a Mine Planning Engineer at Tarkwa Goldfields Limited, Oil Production Assistant at offshore Saltpond, Ghana and with C Deilmann, Nordhorn, Germany. He is currently a Senior Lecturer at University of Mines and Technology, Tarkwa, Ghana and lectures in Oil Well Drilling Technology, Mine Planning and Design and Computer Applications in mining.

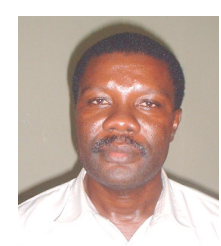

Victor A. Temeng is an Associate Professor in Mining Engineering at the University of Mines and Technology, Tarkwa. He obtained his BSc (Hons.) and Postgraduate Diploma in Mining Engineering degrees from the University of Mines and Technology in 1985 and 1986 respectively. He obtained his MSc degree from the University of Zambia in 1992 and his $\mathrm{PhD}$ degree from the Michigan Technological University, USA in 1997. He joined the University as a Lecturer in 1990. His areas of specialisation include Operations Research, Materials Handling and Computer Applications. 